\title{
Correspondence
}

We welcome letters to the Editor concerning articles which have recently been published. Such letters will be subject to the usual stages of selection and editing; where appropriate the authors of the original article will be offered the opportunity to reply.

Letters should normally be under 300 words in length, double-spaced throughout, signed by all authors and fully referenced. The edited version will be returned for approval before publication.

\section{The timing of reduction and stabilisation of the acute, unstable slipped upper femoral epiphysis}

Sir,

I read with interest the article by Phillips et $\mathrm{al}^{1}$ in the September 2001 issue entitled 'The timing of reduction and stabilisation of the acute, unstable, slipped upper femoral epiphysis'.

The unstable nature of the slip demanded that the stabilisation be carried out urgently to prevent risk of compromise to the blood supply of the epiphysis. Although 24 hours had been decided on as being a safe period, I assume that these hips would have been stabilised at the next available operating session. Therefore the period of 24 hours is arbitrary. With a larger sample and more variable prognosis a decision could be made as to whether the operation was more urgent, e.g. within two hours of presentation, and thus be graded with more practical consideration according to CEPOD status.

The most interesting fact is that a reduction of $100 \%$ was achieved in all unstable hips. This was probably because of the acute nature of the slip. Two issues need to be resolved, namely, the technique and amount of force used in achieving closed reduction and the point of abandoning this in favour of open reduction, and secondly, the technique of open reduction used in order not to stretch the posteriorly placed retinacular vessels during the process of reducing the fragments which are often wedged against each other.

\section{J. K. BARBOSA, MS Ortho, FRCS}

Hope Hospital

Manchester, UK.

1. Phillips SA, Griffiths WEG, Clarke, NMP. The timing of reduction and stabilisation of the acute, unstable, slipped upper femoral epiphysis. J Bone Joint Surg [Br] 2001;83-B:1046-9.

\section{Author's reply:}

Sir,

We thank Mr Barbosa for his interest in our article.

Clearly, the imperative is to reduce the slip as soon as possible but before 24 hours. The message in the paper was that a manipulative reduction was acceptable up to 24 hours.

(C)2003 British Editorial Society of Bone and Joint Surgery

doi.10.1302/0301-620X.85B2.14109 \$2.00

J Bone Joint Surg [Br] 2003;85-B:306-9.
The reductions were achieved either by gentle manipulation or repositioning. Certainly, no force was used and none of the hips was over-reduced. Open reduction was reserved for those cases in which a reduction could not be achieved and yet it was clear that there was an acute slip.

N. M. P. Clarke, CRM, FRCS

Southampton General Hospital

Southampton, UK.

\section{Subtalar distraction bone block arthrodesis}

Sir,

We read with interest the article by Trnka et al ${ }^{1}$ in the August 2001 issue entitled 'Subtalar distraction bone block arthrodesis'.

The authors mentioned 20 feet with avascular necrosis (AVN) of either the talus or the calcaneus. How do they definite AVN? In our series sclerotic bone, found in almost all cases, facilitated stable fixation. ${ }^{2}$ Is it possible to expose the anterior aspect of the subtalar joint using the described approach? Our approach allows a view of all parts of the former subtalar joint. The three corticocancellous grafts correct the deformity creating intrinsic stability even without screw fixation.

Measurement of the talocalcaneal height without the use of a heel-jig could lead to errors because of divergence of the x-ray beam, since the distance between the cassette and the foot often differs. ${ }^{3}$ Placing a radiopaque ruler behind the heel can help to calculate the true heel height from a weight-bearing radiograph. ${ }^{2}$

How do the authors explain the loss of ankle movement? Were there signs of arthritis of the tibiotalar joint? Our series ${ }^{2,4}$ showed that subtalar or triple arthrodesis has little adverse influence on the function of the tibiotalar joint, even after many years.

Although the authors discuss the prominence of internal fixation we believe that this not only affects the results, but is associated with disruption of the heel pad. The 'smashed heel pad syndrome' has been described as a reason for late pain in the heel after fracture of the os calcis by other authors. 5,6 We think that placing screws through this already 'smashed' heel pad could further damage it. By using one lag-screw with a washer from the neck of the talus to the calcaneus, we have not seen secondary settling within the hindfoot during incorporation of the graft. ${ }^{2}$

R. W. POOLMAN, MD

R. K. MARTI, MD, PhD

Academic Medical Centre

Amsterdam, The Netherlands.

1. Trnka H-J, Easley ME, Lam PW-C, et al. Subtalar distraction bone block arthrodesis. J Bone Joint Surg [Br] 2001;83-B:849-54.

2. Marti RK, de Heus JA, Roolker W, Poolman RW, Besselaar PP. Subtalar arthrodesis with correction of deformity after fractures of the os calcis. J Bone Joint Surg [Br] 1999;81-B:611-6.

3. Daffner RH. Clinical radiology: the essentials. 2nd ed. Baltimore, etc: Lippincott Williams \& Wilkins, 1999:8.

4. de Heus JA, Marti RK, Besselaar PP, Albers GH. The influence of subtalar and triple arthrodesis on the tibiotalar joint: a long-term followup study. J Bone Joint Surg [Br] 1997;79-B:644-7.

5. Pozo JL, Kirwan EOG, Jackson AM. The long-term results of conservative management of severely displaced fractures of the calcaneus. J Bone Joint Surg [Br] 1984;66-B:386-90.

6. Lim EV, Leung JP. Complications of intra-articular calcaneal fractures. Clin Orthop 2001;391:7-16. 
Authors' reply:

\section{Sir}

We thank Dr Poolman and Dr Marti for their interest in our article. We noted that avascular changes of the subtalar joint were not uncommon after trauma. These do not amount to avascular necrosis as we understand it, for example, with respect to the body of the talus. Nonetheless, in the 20 feet with avascular changes, this term was applied specifically to the hard, dense, and sclerotic appearance of the subchondral bone surface which did not bleed at operation. They found that sclerotic bone in their series aided fixation, and this is an accurate observation because sclerosis of this region of the subtalar joint does facilitate stable fixation. Using our approach to the subtalar joint, the posterior facet and the sinus tarsi were visible and accessible. The talar calcaneal height was measured in a standardised manner. While I agree that there could be some error in assessment because of the distance between the $\mathrm{x}$ ray cassette and the foot, all radiographs were obtained in a standardised fashion, before and after operation. Therefore, the differences in measurement remain constant despite the slight variations which may have been introduced because of diversions of the x-ray beam.

Loss of ankle movement after subtalar distraction bone block arthrodesis has been noted by us and other authors. This is probably a result of tightening of the gastrocnemius soleus complex with insertion of the tricortical bone block used for distraction. This did not correlate with any findings of arthritis in the tibiotalar joint. The statement that triple arthrodesis has little adverse influence on the function of the tibiotalar joint is not consistent with our findings or with the literature, which records an incidence of $54 \%$ of arthritic changes in the tibiotalar joint after the triple arthrodesis. I agree with the concept of problems of internal fixation introduced under the plantar aspect of the heel pad for subtalar arthrodesis. In fact, the introduction of a screw from the undersurface of the heel should be avoided for this very reason. The screw is introduced from the posterior aspect of the heel immediately inferior to the insertion of tendo Achillis. While efforts are made to bury the head of the screw flush with the posterior cortical surface of the calcaneus, this is not always applicable, hence the need for removal of the hardware in certain patients.

\section{S. MYERSON, MD}

Union Memorial Hospital

Baltimore, USA.

N. M. P. CLARKE, ChM, FRCS

Southampton General Hospital

Southampton, UK.

\section{Tendinopathy of tendo Achillis}

Sir,

With reference to the review article in the January 2002 issue by Maffulli and Kader entitled 'Tendinopathy of tendo Achillis', ${ }^{1}$ I developed bilateral fusiform tendinopathy of tendo Achillis at the age of 41 years after running for fitness, including marathons, for 22 years.

After reviewing the results of surgery published in the literature, and based on my own experience, I decided that surgery for this MRI-proven diagnosis was not an option for treatment.

I therefore stopped running and lost $8 \mathrm{~kg}$ in weight. There was total resolution of all symptoms and signs 18 months later.

After three years and having gained some weight I began running for fitness once again. The same problem recurred and was confirmed by MRI. I lost $8 \mathrm{~kg}$ in weight and stopped running. After
30 months there was complete resolution of all symptoms and signs.

Six years later I am completely free from symptoms, my basal metabolic index remains at 24 , and alternate cardiorespiratory programmes leave me with a resting pulse of 52. My conclusion is that surgery for fusiform tendinopathy induced by sport is probably only successful because of the resultant physical restriction and rest which it enforces.

P. GIBLIN, FRACS, FA Orth A
Goulburn Street Medical Centre

Liverpool, UK.

1. Maffulli N, Kader D. Tendinopathy of tendo Achillis. J Bone Joint Surg [Br] 2002;84-B:1-8.

\section{Author's reply:}

Sir,

There is little doubt that if the level and intensity of the offending activity are reduced, then attenuation or resolution of the symptoms of a tendinopathy can occur. However, active individuals, training and competing either as amateurs or professionals at a high level, cannot or do not wish to change their activities. In these patients, after an appropriate trial of conservative management, surgery is an option. Our selection criteria for operative management are strict, and reflect our experience as orthopaedic surgeons and as athletes. Finally, notwithstanding the fruitful experience that Mr Giblin has had personally, the only way to produce the ultimate answer to his experience is to perform a randomised, controlled trial which would allow us to formulate evidence-based rather than opinion-based decisions.

N. MAFFULLI, MD, MS, PhD, FRCS Orth

Keele University School of Medicine

Hartshill, UK.

\section{The effect of spinal fusion on the long-term outcome of idiopathic scoliosis}

Sir,

We have read with interest the article in the November 2001 issue by Parsch et al ${ }^{1}$ entitled 'The effect of spinal fusion on the longterm outcome of idiopathic scoliosis'. We agree with the need to compare the outcomes of patients having spinal fusion with those of patients managed non-surgically. Such outcomes are crucial for the advice given to patients with scoliosis in relation to the advantages and the disadvantages of surgery.

Their case-control study suggests that patients with and without spinal fusion have similar long-term outcomes. The two groups, however, differ not only in the pattern of the curve, but also in the size of the curve at the time of management. Since both groups had similar Cobb angles at follow-up, the fused group presumably had much larger curves at the time of surgery ( $86^{\circ}$ in 30 patients) and would have had even larger curves had they not been treated surgically. Although there was no significant correlation between the Cobb angle and a lower spinal score in either group, this may be the case for larger curves.

The authors conclude that "multisegmental spinal fusion does not have an adverse effect on the long-term functional outcome". The length of follow-up was a minimum of five years but the mean duration of follow-up for each group is not mentioned. Examination of the mean age of the groups at the time of assessment shows that the mean follow-up period is evidently much longer. Their conclusion should be viewed with caution given the short follow- 
up period in some patients and the differences between the two groups (curve site and curve size at the time of management). Likewise, when considering degenerative changes as outcome measures the inclusion of patients with a follow-up as short as five years may be misleading.

Another compounding factor which is not declared may be the inclusion of patients with infantile and juvenile idiopathic scoliosis in each of the groups. Early studies on the mortality in idiopathic scoliosis included patients with infantile, juvenile and adolescent idiopathic scoliosis and drew conclusions which were not applicable to patients with adolescent idiopathic scoliosis. ${ }^{2,3}$ The pattern of the curve may also affect the findings and it would be useful to know whether levels of pain and functional activity varied by the site of the curve.

A. A. COLE, BMedSci, FRCS (Trauma \& Orth)

R. G. BURWELL, MD, FRCS

R. K. PRATT, MA, FRCS

J. K. WEBB, FRCS

University Hospital

Nottingham, UK.

1. Parsch D, Gaertner V, Brocai DRC, Carstens C. The effect of spinal fusion on the long-term outcome of idiopathic scoliosis: a case-control study. J Bone Joint Surg [Br] 2001;83-B:1133-6.

2. Nachemson A. A long term follow-up study of non-treated scoliosis. Acta Orthop Scand 1968;39:466-76.

3. Nilsonne U, Lundgren KD. Long-term prognosis in idiopathic scoliosis. Acta Orthop Scand 1968;39:456-65.

\section{Author's reply:}

Sir,

We thank Mr Cole and his colleagues for their interest in our paper. They have raised some important points. There is a difference between the effectiveness and the effect of an extended spinal fusion. The latter is supposed to answer the question: How does a fusion affect spinal function? We agree with Mr Cole and his colleagues that, since the curve will be improved after surgery, the effectiveness and the effect of a fusion cannot be evaluated within the same study, at least not in a matched-pairs analysis including the curve size as matching parameter. Hence, for the purpose of our study, outcome parameters, i.e. the Cobb angle at follow-up, have to be matched. This implies on the other hand that our results are not supposed to impact directly on the indication in favour or against surgery, but to support the orthopaedic surgeon in counselling the patient. Multisegmental spinal fusion, if indicated and successfully performed, will not have an adverse effect on the longterm functional outcome. A $40^{\circ}$ scoliotic spine at follow-up is functioning comparably whether it was previously fused or not.

With regard to the mean duration of follow-up, this information (23 years) was lost during the editing process.

We agree that degenerative changes as outcome measures with a follow-up as short as five years may be misleading. That is why we included the patients' age as a matching parameter. As a consequence, younger patients in both groups with a shorter follow-up were only compared with each other.

Finally, Mr Cole raised an important point regarding different types of scoliosis and the time of onset of idiopathic scoliosis. The papers quoted $^{1,2}$ included different types of scoliosis, so that only $45 \%$ actually had an idiopathic scoliosis. ${ }^{3}$ This is why their conclusions were not applicable to idiopathic scoliosis. In our study only patients with idiopathic scoliosis were included. Nevertheless, the onset of idiopathic scoliosis, especially early onset, is of importance when evaluating the long-term outcome. ${ }^{3}$ Here we had to rely on the information given by the participating patients. We excluded infantile idiopathic scoliosis, but did not differentiate between juvenile and adolescent types. This must be considered when interpreting our results.
The impact of the site of the curve on the long-term outcome was not evaluated. The inclusion of a fourth matching parameter would have markedly reduced the number of patients within our groups. We agree, however, that this would have been of interest.

\section{PARSCH, MD}

The Orthopaedic University Hospital

Heidelberg, Germany

1. Nachemson A. A long-term follow-up study of non-treated scoliosis. Acta Orthop Scand 1968;39:466-76.

2. Nilssone $\mathbf{U}$, Lundgren KD. Long-term prognosis in idiopathic scoliosis. Acta Orthop Scand 1968;39:456-65.

3. Weinstein SL. Natural history. Spine 1999;24:2592-2600.

\section{The floating shoulder: a multicentre study}

Sir

Our journal club read with interest the paper by van Noort et $\mathrm{al}^{1}$ in the August 2001 issue entitled 'The floating shoulder: a multicentre study'.

We note that 28 patients were treated non-operatively and seven operatively, all with plate fixation of the clavicle. None had internal fixation of the scapular glenoid. The results for both groups were similar. Non-operatively treated patients with caudal migration of the scapula did relatively badly.

In the discussion the authors state that: "for a fracture of the clavicle and a caudally displaced fracture of the neck of the scapula, we recommend operative treatment......plate fixation of the clavicle alone does not always seem to be sufficient....in the absence of caudal dislocation of the glenoid, conservative treatment will give a good functional outcome".

No patient underwent operative fixation of the scapula. There was no comparison of non-operative and operative treatment for patients with or without caudal migration of the glenoid. We feel that the authors have not established that fixing the scapula gives better results than non-operative treatment for patients either with or without caudal migration of the glenoid. We do not feel that the results shown justify the implied recommendations to fix the scapula with caudal migration.

\section{S. COLERIDGE, MRCS}

D. RICKETTS, FRCS Orth

Princess Royal Hospital

Haywards Heath, UK.

1. van Noort A, te Slaa RL, Marti RK, van der Werken C. The floating shoulder: a multicentre study. J Bone Joint Surg [Br] 2001;83-B:795-8.

\section{Authors' reply:}

Sir,

We thank Mr Coleridge and Mr Ricketts for their interest in our article.

Our findings justify the recommendation of conservative treatment for patients with a fracture of the clavicle and ipsilateral scapular neck without caudal dislocation.

The results of conservative treatment were poor in the case of a caudally displaced glenoid. We agree that operative treatment for the latter groups, based on our study, is debatable. Although no comparison of operative and conservative treatment is possible, we recommend fixation of the clavicle in patients with a fracture of the clavicle and ipsilateral scapular neck with caudal dislocation. If there is persistent caudal dislocation of the glenoid after fixing the clavicle, we suggest reduction and fixation of the scapular neck, in 
the hope that the results may be better. This advice was indeed based on assumption and not on fact.

A. VAN NOORT, MD

University Hospital of Nijmegen

Nijmegen, The Netherlands.

J. S. MEHTA, MS Orth, D Orth, MCh Orth

Gosforth

Newcastle upon Tyne, UK.

\section{Specificity of the Oxford knee status questionnaire}

Sir,

I read with interest the article in the April 2001 issue by Harcourt et $\mathrm{al}^{1}$ entitled 'Specificity of the Oxford knee status questionnaire'. Unfortunately, aspects of this article are confusing and clarification is required.

The authors state that each question in the Oxford knee score is scored from 0 to 4 . The items are summated so that 0 represents the worst possible status and 48 a normal knee. The Oxford Knee Score is actually scored from 1 to $5 .^{2}$ This in itself would not be a major problem as a percentage of the score could just be added. However, they have also reversed the interpretation of the scoring since an increasing score reflects worsening symptoms according to Dawson et al. ${ }^{2}$

The authors conclude that the coexistence of hip or spinal pathology will significantly alter the absolute score and any change in score after operation. Indeed, the absolute score is very important and hence extreme clarity in the use of scoring systems is required to prevent confusion and to confirm validity. Common sense would suggest that the data presented could be plausible. Unfortunately, since their conclusions are based on data which, if scored correctly, reflect the opposite scenario, they cannot be accepted as valid without clarification.

I realise that this may be a simple misunderstanding on their part, but request that their scoring methods and how such data have been interpreted be clarified, in order to substantiate their findings.
L. UNITT, MCSP, SRP

Birmingham Heartlands \& Solihull NHS Trust

Birmingham, UK.

1. Harcourt WGV, White SH, Jones P. Specificity of the Oxford knee status questionnaire: the effect of disease of the hip or lumbar spine on patients' perception of knee disability. J Bone Joint Surg [Br] 2001;83B:345-7.

2. Dawson J, Fitzpatrick R, Murray D, Carr A. Questionnaire on the perceptions of patients about total knee replacement. J Bone Joint Surg [Br] 1998;80-B:63-9

Authors' reply:

Sir,

Our main concern with the Oxford knee status questionnaire was its lack of specificity for the joint but Ms Unitt's letter concerns another difficulty and that is the polarity and range of scores. Dawson et al ${ }^{1}$ originally recommended that the highest score (60), should go to the knee with the lowest function. The best knee therefore would have the lowest score (12), and scores in the range of 0 to 11 would be meaningless.

We prefer to use the scoring system along a conventional scale in which each of the 12 items is scored from 0 to 4 and the scores are summated, thus giving 0 for the worst possible status and 48 for a normal knee. In our Methods section we very clearly stated this and Ms Unitt is quite correct in emphasising that authors using the Oxford knee score should clearly describe how they use this instrument to avoid any confusion. It should be noted that this method of using the Oxford knee score is now widely used in this format.

\section{S. H. WHITE, DM, FRCS}

P. JONES

W. G. V. HARCOURT, FRCS, FRCS Orth

The Robert Jones and Agnes Hunt Orthopaedic Hospital

Oswestry, UK.

1. Dawson J, Fitzpatrick R, Murray D, Carr A. Questionnaire on the perceptions of patients about total knee replacement. J Bone Joint Surg [Br] 1998;80-B:63-9. 